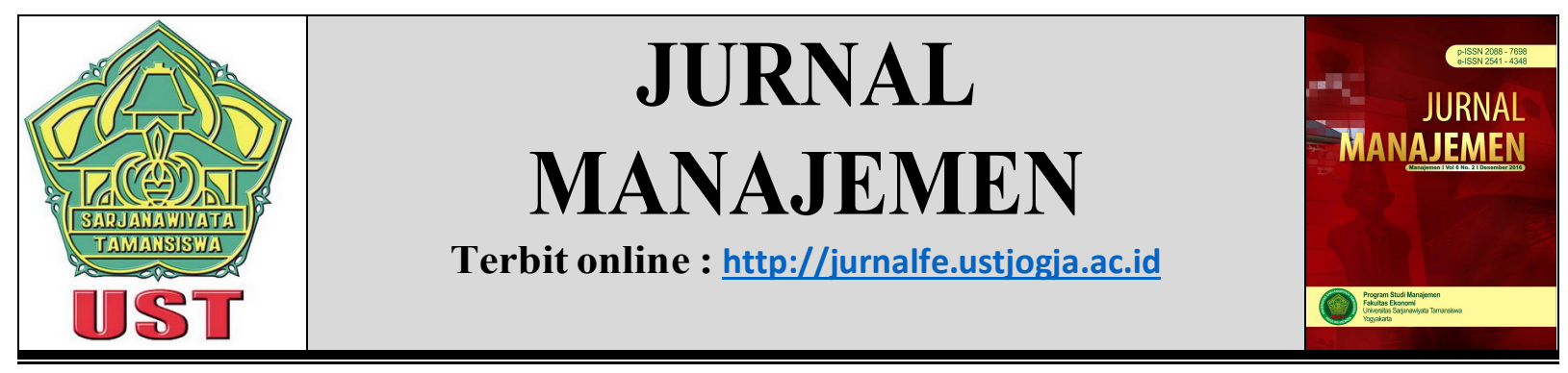

\title{
PENGARUH CELEBRITY ENDORSER TERHADAP KEPUTUSAN PEMBELIAN WISATAWAN YOGYAKARTA PADA PRODUK OLEH- OLEH JOGJA SCRUMMY
}

\author{
Chriswardana Bayu Dewa \\ AMIK BSI Yogyakarta
}

Korespondensi: chriswardana.chb@bsi.ac.id

\begin{tabular}{ll}
\hline Informasi Naskah & Abstrak \\
\hline Diterima: & This study aims to determine whether the celebrity endorser \\
02 Februari & became one of the factors that influence consumer purchase \\
Revisi: & decisions, especially consumers in Indonesia in general and in \\
11 April & Yogyakarta in particular. The data in this study were obtained by \\
Terbit: & distributing questionnaires to 100 respondents in each outlet Jogja \\
16 Mei & scrummy. The data used are primary data sampling technique used \\
\hline Kata Kunci: celebrity & is non-probability sampling. The hypothesis was tested using the \\
endorser, purchase & program Structural Equation Model (SEM). The results showed \\
decision. & that the celebrity endorsement positive influence on purchase \\
& decisions.
\end{tabular}

\section{PENDAHULUAN}

Perkembangan bisnis saat ini menuntut para produsen menggunakan berbagai macam strategi untuk menarik minat konsumen sehingga dapat bertahan di arena persaingan bisnis. Perusahaan secara terus menerus melakukan inovasi untuk mengkomunikasikan produknya agar dapat sesuai dengan kebutuhan dan keinginan konsumen. Promosi penjualan yang baik dan efisien menjadi salah satu strategi pemasaran yang digunakan perusahaan untuk meningkatkan penjualan produknya. Perusahaan melakukan berbagai macam bentuk inovasi dan kreatifitas untuk mempromosikan produknya agar menarik perhatian konsumen. salah satunya adalah dengan cara menggunakan figur seseorang yang memiliki daya tarik, kharisma dan kemampuan untuk menarik pandangan orang banyak. Hal ini disebut dengan celebrity endorser, yaitu publik figur yang diketahui orang banyak karena keahliannya pada bidang tertentu dan memiliki peran untuk berbicara tentang produk, sehingga dapat mempengaruhi sikap dan perilaku konsumen terhadap produk yang didukung (Shimp, 2003). Sosok yang biasanya dapat menjadi celebrity endorser adalah atlet, artis, politikus, budayawan, tokoh masyarakat dan lain-lain yang memilik pengaruh dan dikenal oleh orang banyak. Strategi pemasaran dengan memanfaatkan citra positif seseorang ini diharapkan dapat meningkatkan penjualan produk. 
Sekarang ini banyak sekali produsen menggunakan celebrity endorser untuk membuat produk mereka diterima dipasar. Seperti sepatu merek Nike menggunakan Michael Jordan sebagai icon produk mereka, dengan tujuan membangun persepsi bahwa Michael Jordan bisa menjadi atlet bola basket hebat karena menggunakan sepatu merek Nike. Terdapat 4 faktor yang menyebabkan konsumen tertarik untuk membeli, yaitu kredibilitas selebriti, tingkat disukainya selebriti, daya tarik selebriti dan pengaruh selebriti (Wiryawan dan Pratiwi, 2009). Produsen dapat menggunakan keempat kriteria ini untuk mencari selebriti yang cocok untuk mewakili citra produknya dan dapat diterima oleh pasar. Kamins (1990) mengatakan bahwa keberhasilan strategi celebrity endorser tergantung dari kecocokan citra selebriti dengan produk. Oleh karena itu kesesuaian antara selebriti dengan produk yang tepat dapat membantu untuk membentuk brand personality sehingga dapat mendongkrak nilai penjualan (Royan, 2004). Penggunaan celebrity endorser yang memiliki jutaan followers di akun media sosialnya, dan sedang naik daun, akan sangat mudah untuk membentuk awareness masyarakat terhadap merek yang didukungnya. Choi (2002) mengatakan bahwa faktor yang menjadi fokus utama dalam memilih celebrity endorser adalah popularitas selebriti tersebut.

Yogyakarta merupakan salah satu kota di Indonesia yang memiliki jumlah wisatawan yang cukup banyak. Menurut data dari Disbudparpora dalam www.antarayogya.com, jumlah pengunjung wisatawan yang datang ke Jogja pada saat libur lebaran mencapai 368.656 orang. Hal ini memicu usaha-usaha baru dibidang pariwisata salah satunya adalah usaha oleh-oleh makanan untuk dibawa pulang oleh para pengunjung ke kota mereka masing-masing. Peluang usaha oleh-oleh ini menarik minat artis Dude Herlino untuk membuat oleh-oleh khas Yogyakarta yang diberi merek Jogja Scrummy. Dude Herlino menggunakan citra dirinya sebagai brand endorser produk Jogja Scrummy. Jogja Scrummy berdiri dari tahun 2016 dan baru satu tahun berjalan bisnis ini sudah mempunyai 4 gerai toko di Yogyakarta, yaitu gerai Kaliurang, Malioboro, Katamso dan Adisucipto. Jogja Scrummy saat ini menjadi salah satu oleh-oleh yang dicari oleh wisatawan selain oleh-oleh Bakpia. Fenomena perkembangan bisnis Jogja Scrummy yang begitu cepat membuat peneliti tertarik untuk mendalami apakah celebrity endorser menjadi faktor yang mempengaruhi keputusan pembelian konsumen terhadap produk Jogja Scrummy, dilihat dari indikator kredibilitas, tingkat disukai, daya tarik dan pengaruh Dude Herlino.

\section{KAJIAN PUSTAKA DAN HIPOTESIS}

Celebrity endorser adalah individu yang dikenal oleh banyak orang karena prestasinya di salah satu bidang (aktor, atlet, seniman, dll) untuk mengenalkan produk yang didukung (Friedman et al 1977). Caroll (2009) mendefinisikan celebrity endorser sebagai individu yang diakui oleh publik dan menggunakan pengakuan tersebut atas nama barang-barang konsumsi dengan tampil bersama dalam satu iklan. Selebriti biasanya memiliki penggemar yang dapat digunakan untuk menciptakan pasar. Para penggemar dapat memberikan informasi-informasi tentang kecocokan selebriti dengan produk, dan sikap mereka terhadap produk tersebut sehingga dapat mengarah kepada identifikasi dampak selebriti terhadap citra produk (Belch, 2003).

Celebrity endorsement memiliki indikator-indikator sesuai dengan teori yang dikemukakan oleh Percy dan Rossiter (1987) yaitu VisCAP model (visibility, credibility, attraction, power). Melalui segi visibility, selebriti yang mewakili sebuah produk adalah seseorang yang memiliki kemampuan untuk diperhatikan oleh orang banyak atau publik. Biasanya selebriti yang dipilih adalah orang yang sedang terkenal dan memiliki pengaruh yang 
luas dikalangan masyarakat, sehingga masyarakat dapat tertarik terhadap merek yang diiklankan. Indikator yang selanjutnya adalah kredibilitas, yaitu persepsi masyarakat terhadap kelebihan-kelebihan dari selebriti endorser, sehingga diterima dan diikuti oleh masyarakat. Terdapat dua faktor yang membentuk kredibilitas seseorang, yaitu keahlian dan kepercayaan. Keahlian menunjukan seberapa luas pengetahuan atau kemampuan yang dimiliki oleh endorser, sedangkan kepercayaan menunjukkan seberapa jujur endorser dalam membawakan sebuah iklan. Dari segi attraction terdapat dua karakteristik, yaitu kepesonaan (likability) dan kesamaan (similiarity). Kepesonaan (likability) merupakan karakteristik dari sisi penampilan fisik dan kepribadian, sehingga melalui daya tarik dari endorser dapat membawa dampak positif terhadap merek yang diwakilinya. Sedangkan kesamaan (similiarity) merupakan kesamaan gambaran emosional endorser dalam iklan, sehingga membantu khalayak tertarik pada komunikator yaitu endorser. Indikator terakhir dari VisCAP model adalah power yaitu besarnya pengaruh yang dimiliki oleh endorser terhadap masyarakat. Semakin besar pengaruhnya, semakin masyarakat mempercayai produk yang dibawanya.

Menurut Kotler dan Keller (2009) Keputusan pembelian merupakan proses panjang yang dimiliki konsumen dalam mempertimbangkan keinginanannya terhadap produk atau merek yang berada di pasar. Mereka mengembangkan lima tahap proses keputusan pembelian, yaitu pengenalan masalah, pencarian informasi, evaluasi alternatif, keputusan pembelian dan perilaku pascapembelian. Proses pertama pengenalan masalah, proses pembelian dimulai pada saat konsumen menyadari suatu masalah, sehingga menimbulkan kebutuhan, sampai kepada tingkat maksimum menjadi suatu dorongan untuk memenuhi kebutuhan tersebut. Proses kedua pencarian informasi, konsumen menggunakan berbagai sumber informasi untuk mengetahui produk yang terbaik dalam memenuhi kebutuhannya. Sumber informasi tersebut adalah pribadi (keluarga, teman, tetangga, rekan), komersial (iklan, situs web, wiraniaga, penyalur, kemasan, tampilan), publik (media massa, organisasi, pemeringkat konsumen) dan eksperimental (penanganan, pemeriksaan, penggunaan produk). Proses ketiga evaluasi alternatif, beberapa konsep dasar yang membantu konsumen dalam mengevaluasi yaitu konsumen berusaha memuaskan sebuah kebutuhan, konsumen mencari manfaat tertentu dari solusi produk, dan konsumen melihat masing-masing produk sebagai atribut dengan berbagai kemampuan untuk memberi manfaat yang diperlukan dalam memuaskan kebutuhan. Proses keempat yaitu pengambilan keputusan, terdapat dua alat persuasi pengambilan keputusan yaitu rute pusat, dimana perubahan sikap merangsang pertimbangan cermat dan rasional tentang informasi produk terpenting; dan rute periferal, dimana perubahan sikap mendorong sedikit pikiran kepada hal-hal yang berkaitan dengan asosiasi merek dengan pertanda periferal (dukungan selebriti, sumber yang kredibel, dll.) negatif atau positif. Proses kelima perilaku pascapembelian, setelah pembelian, konsumen mungkin merasa tidak puas terhadap fitur dari produk yang telah dimilikinya, sehingga tertarik untuk menggunakan merek lain, karena itu tugas pemasar tidak berakhir dengan pembelian. Pemasar harus mengamati kepuasan pascapembelian, tindakan pascapembelian, dan penggunaan produk pascapembelian.

Hipotesis dalam penelitian ini, terbagi dalam hipotesis utama yaitu pengaruh celebritry endorser terhadap keputusan pembelian, dan sub-hipotesis yaitu pengaruh indikator-indikator pembentuk celebrity endorser (VisCAP) terhadap keputusan pembelian.

H1 : Celebrity endorser berpengaruh positif terhadap keputusan pembelian.

H1.1 : Visibility berpengaruh positif terhadap keputusan pembelian.

H1.2 : Credibility berpengaruh positif terhadap keputusan pembelian.

H1.3 : Attraction berpengaruh positif terhadap keputusan pembelian. 
H1.4 : Power berpengaruh positif terhadap keputusan pembelian.

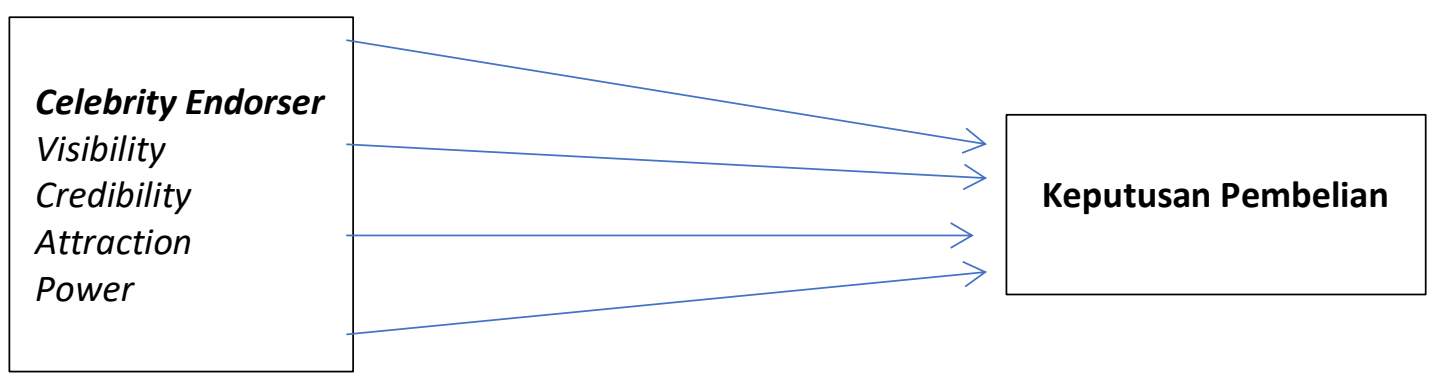

\section{Gambar 1 \\ Model Hipotesis}

\section{METODE PENELITIAN}

Data yang digunakan dalam penelitian ini adalah data primer dengan metode membagikan kuesioner, dan meminta responden untuk mengisi kuesioner tersebut. Metode pemilihan sampel yang digunakan adalah non-probability sampling yang terdiri dari 100 orang dari wisatawan lokal maupun asing yang membeli produk Jogja Scrummy di Yogyakarta. Penelitian ini dilakukan di empat gerai Jogja Srcummy di Yogyakarta, yaitu gerai Jalan Kaliurang, Malioboro, Katamso dan Adisucipto. Pengujian validitas dalam penelitian ini menggunakan alat ukur analisis faktor dari program SPSS 16. Reliabilitas dalam penelitian ini diuji dengan menghitung cronbach's alpha dengan menggunakan alat uji program SPSS 16. Untuk menguji hipotesis peneliti menggunakan SEM dengan bantuan program AMOS 16.0. Pengujian hipotesis H1.1,H1.2,H1.3, dan H1.4 dengan menggunakan SEM diuji dengan melihat significant path pada penelitian.

\section{HASIL DAN PEMBAHASAN}

Dalam penelitian ini peneliti menguji validitas dan ditemukan hasil bahwa setiap item pertanyaan setiap variabel valid, sehingga dapat dipakai untuk tahap selanjutnya yaitu pengujian hipotesis.

\section{Tabel 1}

Hasil Uji Validitas Indikator Visibility

\begin{tabular}{|c|l|c|c|}
\hline Kode & \multicolumn{1}{|c|}{ Item Pernyataan } & $\begin{array}{c}\text { Faktor } \\
\text { Loading }\end{array}$ & Status \\
\hline V1 & Dude Herlino sebagai artis yang populer & 0,835 & Valid \\
\hline V2 & Dude Herlino memiliki kepribadian yang menarik & 0,865 & Valid \\
\hline V3 & $\begin{array}{l}\text { Dude Herlino merupakan sosok selebriti yang dipandang } \\
\text { memiliki perilaku yang baik }\end{array}$ & 0,881 & Valid \\
\hline
\end{tabular}

Tabel 2

\section{Hasil Uji Validitas Indikator Credibility}

\begin{tabular}{|c|l|c|c|}
\hline Kode & \multicolumn{1}{|c|}{ Item Pernyataan } & $\begin{array}{c}\text { Faktor } \\
\text { Loading }\end{array}$ & Status \\
\hline C1 & $\begin{array}{l}\text { Dude Herlino memiliki pengetahuan dan keahlian dalam } \\
\text { mengkomunikasikan produk }\end{array}$ & 0,698 & Valid \\
\hline
\end{tabular}




\begin{tabular}{|c|l|c|c|}
\hline C2 & $\begin{array}{l}\text { Dude Herlino memiliki kemampuan untuk meyakinkan } \\
\text { bahwa Jogja Scrummy merupakan produk oleh-oleh } \\
\text { khas Yogyakarta yang lezat }\end{array}$ & 0,662 & Valid \\
\hline C3 & $\begin{array}{l}\text { Dude Herlino merupakan sosok selebriti yang dapat } \\
\text { dipercaya dalam mengkomunikasikan iklan kepada } \\
\text { responden }\end{array}$ & 0,674 & Valid \\
\hline
\end{tabular}

Tabel 3

Hasil Uji Validitas Indikator Attraction

\begin{tabular}{|c|l|c|c|}
\hline Kode & \multicolumn{1}{|c|}{ Item Pernyataan } & $\begin{array}{c}\text { Faktor } \\
\text { Loading }\end{array}$ & Status \\
\hline A1 & Dude Herlino memiliki daya tarik secara fisik & 0,735 & Valid \\
\hline A2 & $\begin{array}{l}\text { Dude Herlino merupakan sosok yang dipandang mampu } \\
\text { memikat dan memukau responden dalam setiap iklan, } \\
\text { film, dan aktivitas entertain yang dibintanginya }\end{array}$ & 0,883 & Valid \\
\hline A3 & $\begin{array}{l}\text { Dude Herlino sebagai sosok yang mampu memberikan } \\
\text { inspirasi kepada responden }\end{array}$ & 0,675 & Valid \\
\hline
\end{tabular}

Tabel 4

Hasil Uji Validitas Indikator Power

\begin{tabular}{|c|l|c|c|}
\hline Kode & \multicolumn{1}{|c|}{ Item Pernyataan } & $\begin{array}{c}\text { Faktor } \\
\text { Loading }\end{array}$ & Status \\
\hline P1 & $\begin{array}{l}\text { Dude Herlino merupakan sosok selebritis yang patut } \\
\text { diteladani oleh responden }\end{array}$ & 0,565 & Valid \\
\hline P2 & $\begin{array}{l}\text { Dude Herlino merupakan sosok selebriti yang mampu } \\
\text { dijadikan idola }\end{array}$ & 0,572 & Valid \\
\hline
\end{tabular}

\section{Tabel 5}

Hasil Uji Validitas Variabel Keputusan Pembelian

\begin{tabular}{|c|l|c|c|}
\hline Kode & \multicolumn{1}{|c|}{ Item Pernyataan } & $\begin{array}{c}\text { Faktor } \\
\text { Loading }\end{array}$ & Status \\
\hline KP1 & $\begin{array}{l}\text { Saya memutuskan membeli produk oleh-oleh Jogja } \\
\text { Srummy karena kebutuhan }\end{array}$ & 0,576 & Valid \\
\hline KP2 & $\begin{array}{l}\text { Saya memutuskan membeli produk oleh-oleh Jogja } \\
\text { Scrummy karena ingin mencobanya }\end{array}$ & 0,620 & Valid \\
\hline KP3 & $\begin{array}{l}\text { Saya terbiasa membeli Jogja Scrummy untuk oleh-oleh } \\
\text { setiap kali ke Yogyakarta. }\end{array}$ & 0,681 & Valid \\
\hline
\end{tabular}

Berdasarkan hasil uji validitas terlihat bahwa nilai indikator-indikator pembentuk variabel celebrity endorser dan variabel keputusan pembelian mendapatkan hasil nilai diatas atau $>0,5$. Maka dapat ditarik kesimpulan bahwa semua indikator dan variabel dalam pengujian validitas ini dinyatakan valid dan dapat digunakan untuk di ukur dalam penelitian ini. Setelah melakukan uji validitas, data pada item pertanyaan yang valid diuji reliabilitasnya menggunakan metode cronbach's alpha. Pada dasarnya uji reliabilitas menunjukkan sejauh mana sebuah alat 
ukur dapat memberikan hasil yang sama apabila dilakukan pengukuran kembali pada subjek yang sama. Berdasarkan pengujian didapat bahwa indikator variabel celebrity endorser (visibility, credibility, attraction, power) dan variabel keputusan konsumen adalah reliabel. Hasil output uji reliabilitas dapat dilihat pada tabel 6 berikut ini :

Tabel 6

Hasil Uji Reliabilitas

\begin{tabular}{|c|c|c|}
\hline Variabel & Cronbach alpha & Kategori \\
\hline Visibility & 0,755 & Reliabilitas diterima \\
\hline Credibility & 0,666 & Reliabilitas diterima \\
\hline Attraction & 0,727 & Reliabilitas diterima \\
\hline Power & 0,671 & Reliabilitas diterima \\
\hline Keputusan Konsumen & 0,766 & Reliabilitas diterima \\
\hline
\end{tabular}

Sebelum hipotesis diuji, terlebih dahulu dilakukan pengujian model fit, dengan tujuan untuk menentukan kesesuaian model dengan data. Pada penelitian ini dapat terlihat nilai-nilai absolute fit yang menunjukkan bahwa secara umum model mempunyai goodnes of fit yang cukup baik, sehingga pengujian hipotesis dapat dilakukan dengan model yang ada. Berikut hasil dari model fit dalam penelitian ini.

Tabel 7

Hasil Pengujian Model Fit

\begin{tabular}{|c|c|c|c|}
\hline $\begin{array}{c}\text { Goodness-of-fit } \\
\text { Index }\end{array}$ & Kriteria & Hasil Olah Data & $\begin{array}{c}\text { Evaluasi } \\
\text { Model }\end{array}$ \\
\hline Chi Square & Tidak signifikan & 150 & Kurang baik \\
\hline CMIN/DF & $1-2$ over fit, 2-5 liberal limit & 1,195 & Baik \\
\hline GFI & $>0,90$ & 0,874 & Cukup \\
\hline AGFI & $>0,80$ & 0,830 & Baik \\
\hline TLI & $>0,9$ & 0,983 & Baik \\
\hline CFI & $>0,9$ & 0,986 & Baik \\
\hline RMSEA & $<0,08$ upper limit $<0,1$ & 0,041 & Baik \\
\hline
\end{tabular}

Setelah model penelitian sesuai dengan data, maka dapat dilakukan pengujian hipotesis untuk H1.1, H1.2, H1.3, dan H1.4, dengan melihat siginificant path. Hasil pengujian hipotesis dapat dilihat pada tabel 8 berikut ini,

Tabel 8

Hasil Uji Hipotesis

\begin{tabular}{|l|l|c|c|c|}
\hline No. & \multicolumn{1}{|c|}{ Isi Hipotesis } & $\begin{array}{c}\text { Standardized } \\
\text { Regression } \\
\text { Weights }\end{array}$ & P & Keterangan \\
\hline H1.1 & $\begin{array}{l}\text { Visibility berpengaruh } \\
\text { positif terhadap } \\
\text { keputusan pembelian }\end{array}$ & 0,422 & $<0,01$ & Hipotesis diterima \\
\hline H1.2 & Credibility & 0,356 & $<0,01$ & Hipotesis diterima \\
\hline
\end{tabular}




\begin{tabular}{|l|l|c|c|c|}
\hline & $\begin{array}{l}\text { berpengaruh positif } \\
\text { terhadap keputusan } \\
\text { pembelian }\end{array}$ & & & \\
\hline H1.3 & $\begin{array}{l}\text { Attraction } \\
\text { berpengaruh positif } \\
\text { terhadap keputusan } \\
\text { pembelian }\end{array}$ & 0,451 & $<0,01$ & Hipotesis diterima \\
\hline H1.4 & $\begin{array}{l}\text { Power berpengaruh } \\
\text { positif terhadap } \\
\text { keputusan pembelian }\end{array}$ & 0,231 & $<0,01$ & Hipotesis diterima \\
\hline
\end{tabular}

Pada tabel 8 ditemukan bahwa indikator visibility berpengaruh positif terhadap keputusan pembelian $(\beta=0,422, \mathrm{P}<0,05)$. Hasil ini menyimpulkan bahwa visibility berpengaruh signifikan terhadap keputusan pembelian, sehingga peningkatan visibility akan meningkatkan keputusan pembelian konsumen. Hal ini berarti bahwa Dude Herlino sebagai celebrity endorser berhasil mewakili produk Jogja Scrummy di mata konsumen. Dude Herlino dianggap sebagai selebriti yang populer, berkepribadian menarik dan dipandang memiliki perilaku yang baik, sehingga mampu mewakili produk yang dibawanya dan membuat konsumen memutuskan membeli produk tersebut . Hal ini mendukung pernyataan teori dari Percy dan Rossiter (1987) bahwa melalui segi visibility, selebriti yang mewakili sebuah produk merupakan seseorang yang memiliki kemampuan untuk diperhatikan oleh orang banyak atau publik.

Credibility berpengaruh positif terhadap keputusan pembelian $(\beta=0,356, \mathrm{P}<0,05)$. Hasil ini menyimpulkan bahwa credibility berpengaruh signifikan terhadap keputusan pembelian, sehingga peningkatan credibility akan meningkatkan keputusan pembelian konsumen. Hal ini berarti Dude Herlino dianggap sebagai selebriti yang memilliki pengetahuan dan keahlian dalam mengkomunikasikan produk Jogja Scrummy dimata konsumen, memiliki kemampuan untuk meyakinkan konsumen, dan dapat dipercaya oleh konsumen. Hal ini sesuai dengan teori Percy dan Rossiter (1987) bahwa terdapat dua faktor yang membentuk kredibilitas seseorang, yaitu keahlian dan kepercayaan. Keahlian menunjukan seberapa luas pengetahuan atau kemampuan yang dimiliki oleh endorser, sedangkan kepercayaan menunjukkan seberapa jujur endorser dalam membawakan sebuah iklan.

Attraction berpengaruh positif terhadap keputusan pembelian $(\beta=0,451, \mathrm{P}<0,05)$. Hasil ini menyimpulkan bahwa attraction berpengaruh signifikan terhadap keputusan pembelian, sehingga peningkatan attraction akan meningkatkan keputusan pembelian konsumen. Hal ini menunjukkan bahwa Dude Herlino dianggap sebagai selebriti yang menarik secara fisik, mampu memikat dan memberi inspirasi kepada konsumen, sehingga konsumen memutuskan untuk melakukan pembelian. Sesuai dengan teori Percy dan Rossiter (1987) bahwa segi attraction memiliki dua karakteristik, yaitu kepesonaan (likability) dan kesamaan (similiarity). Kepesonaan (likability) merupakan karakteristik dari sisi penampilan fisik dan kepribadian, sehingga melalui daya tarik dari endorser dapat membawa dampak positif terhadap merek yang diwakilinya. Sedangkan kesamaan (similiarity) merupakan kesamaan gambaran emosional endorser dalam iklan, sehingga membantu khalayak tertarik pada komunikator yaitu endorser.

Power berpengaruh positif terhadap keputusan pembelian $(\beta=0,231, \mathrm{P}<0,05)$. Hasil ini menyimpulkan bahwa power berpengaruh signifikan terhadap keputusan pembelian dengn besaran pengaruh yang kecil, sehingga peningkatan power akan meningkatkan keputusan pembelian konsumen tapi tidak memiliki pengaruh yang besar. Hal ini menunjukkan bahwa 
Dude Herlino sedikit mampu memberikan pengaruh dan teladan bagi konsumen, sehingga konsumen memutuskan untuk membeli produk yang diiklankan oleh Dude Herlino. Dalam VisCAP model yang dikemukakan oleh Percy dan Rossiter (1987), menunjukkan kesesuaian dengan hasil penelitian ini, khususnya dari segi power, yaitu semakin besar pengaruh seorang endorser, semakin masyarakat mempercayai produk yang dibawanya.

Variabel yang berpengaruh dominan terhadap keputusan pembelian adalah visibility dengan nilai beta 0,422 , sehingga memiliki pengaruh yang paling besar daripada variabel lainnya.

\section{PENUTUP}

Berdasarkan hasil penelitian, menunjukkan bahwa semua indikator pembentuk celebrity endorser memiliki pengaruh yang signifikan terhadap keputusan pembelian, sehingga dapat disimpulkan bahwa variabel celebrity endorser dapat mempengaruhi variabel keputusan pembelian. Semakin baik visibility, credibility, attraction, dan power selebriti maka akan meningkatkan keputusan pembelian konsumen. Dari hasil penelitian ditemukan bahwa indikator visibility memiliki pengaruh paling dominan terhadap keputusan pembelian konsumen. Hal ini berarti seorang selebriti yang memiliki kemampuan untuk diperhatikan oleh orang banyak atau publik, menjadi salah satu faktor yang mendorong konsumen untuk memutuskan membeli produk yang diwakili oleh selebriti tersebut.

Menurut penelitian ini, Dude Herlino sebagai celebrity endorser produk oleh-oleh Jogja Scrummy memenuhi semua indikator celebrity endorser. Dude Herlino dianggap oleh konsumen sebagai artis yang dipandang baik, dapat dipercaya, menarik dan memiliki pengaruh, sehingga konsumen memutuskan untuk membeli produk yang diwakilkan oleh Dude Herlino. Maka dari itu, dapat disimpulkan bahwa salah satu faktor yang meningkatkan penjualan Jogja Scrummy disebabkan oleh citra Dude Herlino sebagai celebrity endorser yang berhasil mewakili produk tersebut.

Dari hasil penelitian ini variabel celebrity endorser memiliki pengaruh yang signifikan terhadap keputusan pembelian. Celebrity endorser hanya salah satu faktor yang mempengaruhi keputusan pembelian konsumen, masih banyak faktor lain yang menjadi pendukung keputusan pembelian konsumen. Peneliti merekomendasikan kepada penelitian berikutnya untuk menambah variabel-variabel lain yang dapat menjelaskan lebih detail tentang keputusan pembelian konsumen. Peneliti juga merekomendasikan kepada perusahaan untuk memperhatikan unsur visibility selebriti yang akan mewakilkan dan mengkomunikasikan produknya, karena indikator ini yang memiliki pengaruh yang paling besar sebagai pertimbangan konsumen sebelum memutuskan untuk membeli.

\section{REFERENSI}

Belch, George, E., \& Michael. A.B. (2003). "Advertising and Promotion: An Integrated Marketing Communication Perspective", International Edition, New York : McGraw Hill.

Caroll. Angela. (2009). "Brand Communication in Fashion Categories Using Celebrity Endorsement", Journal of Brand Management. Vol.17 No.2, pp. 146-158.

Choi, Sejung Marina. (2002). "Attributional Approach to Understanding Celebrity/Product Congruence Effects : Role of Perceived Expertis.", Available on : http:/search.proquest.com/docview/252240847/fulltextPDF. (diakses tanggal 10 Februari 2017). 
Friedman, H., Salvatore. T., and Robert, W. (1977). "The Effectiveness of Advertisements Utilizing Four Types of Endorsers", Journal of Advertising , 22, 29-30.

Kamins, Michael A. (1990). "An Investigation into the 'Match-Up' Hypotesis in Celebrity Advertising: When Beauty May Be Only Skin Deep”, Journal of Advertising, 19 (1), 413

Kotler, P., dan K. L Keller (2009). “Manajemen Pemasaran Jilid II edisi 13”. Jakarta: Erlangga.

Percy, L., and Rossiter, J. R. (1987). “Advertising and Promotion Management”, McGraw-Hill: Singapore.

Royan Frans M. (2004). "Sales Force (Meningkatkan Penjualan dengan Rancangan Bangun Sales Force Effective)". Yogyakarta: Penerbit Andi Offset.

Shimp, T.A. (2003). "Periklanan Promosi, Aspek Tambahan Komunikasi Pemasaran Terpadu", Jakarta: Erlangga.

Sutarmi. (2017). "Lebaran 2017-Dispar:Jumlah Wisatawan H+3 Mencapai 63.585 Pengunjung", https://jogja.antaranews.com/berita/347217/lebaran-2017-dispar-jumlahwisatawan-h3-mencapai-63585-pengunjung, (diakses tanggal 13 Februari 2017)

Wiryawan, D., dan Pratiwi, A. (2009). "Analisis Pengaruh Selebriti Endorser Terhadap Brand Image pada Iklan Produk Kartu Prabayar XL Bebas di Bandar Lampung”, Jurnal Bisnis dan Manajemen 5 (3). 